\section{Evidence-based dentistry - overcoming the challenges for the UK's dental practitioners}

\author{
C. Fox, ${ }^{* 1}$ E. J. Kay ${ }^{2}$ and R. Anderson ${ }^{3}$
}

IN BRIEF

- Reviews the history of evidence-based dentistry.

- Summarises the remaining obstacles to evidence-based dental practice.

- Argues that primary dental care practitioners should be directly involved in setting the research agenda.

- Describes the introduction of a new process for rapid review of the available literature on topics prioritised by dental practitioners.

This paper describes the historical origins and purpose of 'evidence-based practice' and describes the barriers to the growth of evidence-based practice within dentistry. It describes a new research agenda-setting process for dentistry, which includes identifying and prioritising the topics of most relevance to the work of primary dental care practitioners. By undertaking the work described in this paper we were striving to make research more relevant to the day to day decisions made by dentists in practice by introducing a new process, the intention being to promote and promulgate the practice of evidence-based dentistry.

\section{INTRODUCTION: THE ORIGINS AND ASPIRATIONS OF EVIDENCE-BASED DENTISTRY}

Widespread lack of understanding of the effects of healthcare was first clearly set out by Archie Cochrane in his book Effectiveness and efficiency: random reflections of health services, published in 1971. ${ }^{1}$ This publication set in motion a huge paradigm shift that underpinned perhaps the single most significant change in how clinical decisions are made that has occurred in modern times.

Effectiveness and efficiency pointed out that the NHS's 'cure' output was less than should be expected, given the economic input, and that scientific approaches to diagnosis and treatment would improve this situation. Most particularly Cochrane advocated the widespread use of randomised controlled trials. His assertion was that by doing this, the use of ineffective interventions would reduce and effective interventions would be utilised more efficiently (Table 1 ).

Recent refinement of the Cochrane concept has acknowledged that research

\footnotetext{
Researcher, Collaboration for the Advancement of Medical Education Research \& Assessment (CAMERA), Plymouth University, Peninsula Schools of Medicine and Dentistry, Portland Square, Drake Circus, Plymouth, PL4 $8 \mathrm{AA} ;{ }^{2}$ Foundation Dean and Professor of Dental Public Health, Public Health Academic Consultant, Plymouth University, Peninsula Schools of Medicine and Dentistry: ${ }^{3}$ Associate Professor of Health Economics and Evaluation, Peninsula Technology Assessment Group, University of Exeter Medical School, University of Exeter ${ }^{*}$ Correspondence to: C. Fox

Email: chris.fox@plymouth.ac.uk
}

\section{Refereed Paper}

Accepted 19 June 2014

DOI: 10.1038/sj.bdj.2014.703

British Dental Journal 2014; 217: 191-194 evidence alone is not an adequate basis for clinical decision making. There has been increasing recognition that the clinician has a personal expertise to add into the decision equation and that the patient's concerns and preferences are also highly relevant to the achievement of positive outcomes. This more developed model of evidence-based practice was elegantly summarised in the 2003 Sicily Statement, ${ }^{2}$ which stated that evidence-based practice required that 'decisions about healthcare are based on the best available current valid and relevant evidence. These decisions should be made by those receiving care, informed by the tacit and explicit knowledge of those providing care, within the context of the available resources'. Figure 1 highlights the old and new philosophies of medical practice. ${ }^{3}$

The first Cochrane Centre, which organises and quality assures systematic

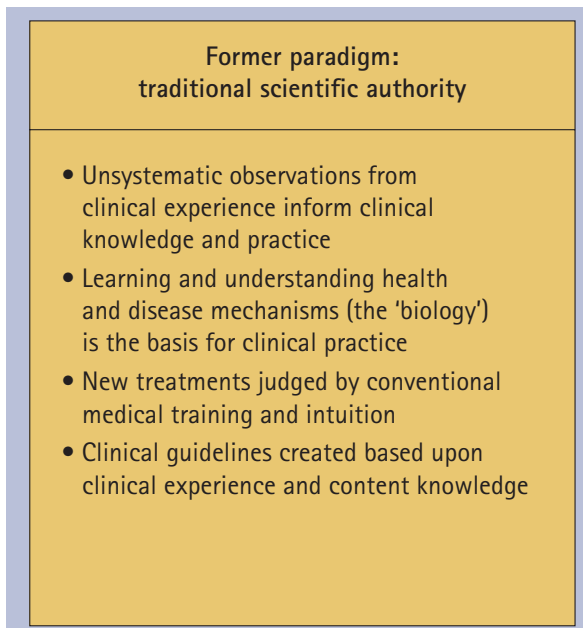

\section{Table 1 Cochrane's applied research priorities (1971)}

To halt introduction of new drugs or therapies (to the NHS) unless they are more effective/as effective, but cheaper than existing approaches.

To assess existing therapies and to exclude the ineffective or too dangerous.

To identify the most appropriate use of therapies where uncertainty exists.

To quantify optimal duration of any hospital admission.

reviews of healthcare randomised controlled trials, was launched in 0xford in 1992. Subsequently in 1995 The Cochrane Collaboration published a handbook of systematic reviewing, and since then multiple international specialist groups, including the Cochrane Oral Health Group have been set up. Online reference searching and retrieval software were created by the

\begin{tabular}{l} 
New paradigm: \\
understand the underlying evidence \\
\hline - Systematic observation to underpin \\
diagnostic testing, teatment efficacy \\
and patient prognosis - combined with \\
clinical experience \\
- Learning and understanding the 'biology' \\
is essential but insufficient for accurate \\
predictions of diagnostic testing and \\
treatment efficacy \\
- To appreciate the 'rules of evidence' to \\
understand and interpret clinical literature \\
- regular consultation and critical appraisal \\
of literature required to solve clinical \\
issues and provide quality care
\end{tabular}

Fig. 1 Paradigm shift: old and new philosophies of medical practice 
Collaboration and The Cochrane Database of Systematic Reviews and the Cochrane Trials Register and Cochrane Library followed. By May 2012, 5,044 reviews had been published and 2,183 protocols for systematic reviews had been established.

\section{BARRIERS TO THE IMPLEMENTATION OF EVIDENCE- BASED PRACTICE IN DENTISTRY}

Various initiatives have attempted to reduce the obstacles practitioners face in adopting the evidence-based philosophy and applying it to the clinical care they give. Identification of these barriers is the first step towards making practice based on research evidence the norm rather than the exception (Table 2).

\section{RESEARCH WASTE}

A further barrier to evidence-based practice is 'research waste'. Failure of research to address the questions that matter to clinicians, and repetition of studies for which quality evidence already exists, are two of the greatest sources of research 'waste.. ${ }^{18}$ Therefore improving systems of research prioritisation so that the 'right' questions are funded is of great importance if practitioners are expected to treat patients according to research findings. Equally, to avoid the waste caused by repetition of studies, a system of examining the current state of evidence about a prioritised question would seem to be a fundamental pre-requisite to any research funding decision. Given that the funding for dental research is very limited in availability, avoidance of any research 'waste' in dentistry would seem to be of particular importance (Fig. 2).

While the notion of evidence-based practice is clearly a good one, at the level of the individual dental practitioner there is a huge challenge. The volume of research that can inform dental practice is enormous. For example in 2002 there were 460,000 dental articles available through MEDLINE and similar levels $(423,500)$ at January $2014 .{ }^{19}$ It is therefore simply not possible for individual clinicians to read, make sense of, and translate all of current research into action in day to day work. Thus, sources of summarised reviews of treatment effectiveness are important in facilitating evidence-based practice. Pre-processed evidence that is relevant to everyday clinical work is comparatively rare, although the volume of it is growing. The size of the knowledge base is not, however, the only barrier to evidence-based practice and it is clear that having access to the evidence is insufficient in itself to change practice. ${ }^{20}$ Other barriers include a complete lack of relevant and robust research evidence in some parts of clinical dental practice. ${ }^{6}$

\section{Table 2 Barriers to evidence-based dentistry}

\begin{tabular}{|c|c|}
\hline Barrier & Description/illustration of barrier to evidence based practice \\
\hline $\begin{array}{l}\text { Lack of awareness of } \\
\text { current best evidence }\end{array}$ & $\begin{array}{l}\text { 'Gridlock' in using research in practice partly relates to practitioners' lack of aware- } \\
\text { ness of, or familiarity with, research evidence. 'It is clear that most clinicians either } \\
\text { do not have access to or are not capable of evaluating the primary literature't,5 }\end{array}$ \\
\hline $\begin{array}{l}\text { Lack of good quality } \\
\text { evidence }\end{array}$ & $\begin{array}{l}89 \text { systematic reviews of evidence on the Cochrane oral health database. Perhaps } \\
\text { only } 13 \text { of them relate to routine operative or periodontal procedures, which } \\
\text { account for about } 70 \% \text { of units of dental activity (UDAs). 'What are we to do } \\
\text { when the irresistible force of the need to offer clinical advice meets with the } \\
\text { immovable object of flawed evidence? All we can do is our best: give the advice, } \\
\text { but alert the advisees to the flaws in the evidence on which it is based'.67 }\end{array}$ \\
\hline $\begin{array}{l}\text { of } \\
\text { ital journals }\end{array}$ & $\begin{array}{l}\text { 'Dentists constantly are inundated by scientific information. The proliferation } \\
\text { of scientific information and its dissemination as scientific literature challenges } \\
\text { the dentist if only because of the sheer volume of scientific journal articles. The } \\
\text { number of titles doubles almost every } 10 \text { to } 15 \text { years.,.9. }\end{array}$ \\
\hline $\begin{array}{l}\text { Difficulty for practitioners } \\
\text { to use large and complex } \\
\text { systematic reviews }\end{array}$ & $\begin{array}{l}\text { The bulk and sophistication of large systematic reviews make them impractical } \\
\text { for use by practitioners in consulting rooms. }{ }^{8}\end{array}$ \\
\hline $\begin{array}{l}\text { Limited time within } \\
\text { practice constraints } \\
\text { to embrace all aspects } \\
\text { of EBD }\end{array}$ & $\begin{array}{l}\text { For EBD to be successful in practice, evidence must be available in a timely } \\
\text { manner at the dental chairside. Critically appraised topics (CAT) - paper or } \\
\text { electronic one page summaries of evidence with a summary statement of what } \\
\text { clinical action to take have been tried }{ }^{10}\end{array}$ \\
\hline $\begin{array}{l}\text { Practitioners' resistance } \\
\text { to change }\end{array}$ & $\begin{array}{l}\text { In } 2003 \text {, the ADA reported } 30 \% \text { of its survey respondents were opposed to the } \\
\text { EBP concept, with indications it was perceived to be intrusive or an encroach- } \\
\text { ment upon clinical judgement. In addition, practitioners are hesitant to use } \\
\text { research findings in their practice }{ }^{4,11-13}\end{array}$ \\
\hline $\begin{array}{l}\text { Lack of av } \\
\text { evidence }\end{array}$ & $\begin{array}{l}\text { Evidence may not exist, or the available evidence is too weak to inform } \\
\text { decision-making, or it may have been inadequately evaluated/ understood, or } \\
\text { evidence is not sought. }\end{array}$ \\
\hline $\begin{array}{l}\text { Publication bias in the } \\
\text { available evidence }{ }^{15} \\
\text { Evidence emphasising } \\
\text { quantitative research } \\
\text { designs may reduce clini- } \\
\text { cians' behaviour change }^{16}\end{array}$ & $\begin{array}{l}\text { A lack of understanding exists about the extent to which dental literature is } \\
\text { susceptible to publication bias through, for example, time lag bias } \\
\text { Clinicians appear to value inclusion of some qualitative aspects in evidence- } \\
\text { based publications to enhance understanding and to increase positive EBD } \\
\text { behaviour change and interest for new knowledge. }\end{array}$ \\
\hline External factors ${ }^{5}$ & $\begin{array}{l}\text { Factors outside the clinician's control affect EBD adoption, including access to } \\
\text { particular equipment, the cost of changes in facility design, poor reimburse- } \\
\text { ment, increasing operational costs, liability. }\end{array}$ \\
\hline $\begin{array}{l}\text { Lack of access to } \\
\text { internet or information } \\
\text { technology }\end{array}$ & $\begin{array}{l}\text { In 2009, it was estimated that } 25 \% \text { of UK dental practices did not have basic } \\
\text { computer hardware even for the purposes of collecting data about dental } \\
\text { activity. In addition, patients increasingly use the internet, including social net- } \\
\text { working, to find out about health issues, leading to informed patient opinion } \\
\text { about their care needs and preferences. }\end{array}$ \\
\hline $\begin{array}{l}\text { Systems are lacking to } \\
\text { track experience \& make } \\
\text { scientific evidence more } \\
\text { relevant to their own } \\
\text { practices }^{17}\end{array}$ & $\begin{array}{l}\text { Practitioners rely upon clinical experience, colleague opinion \&t online summary } \\
\text { evidence. EBP is averaged global evidence (exogenous) derived from external } \\
\text { populations and may lack relevance to local circumstances. Collecting local } \\
\text { evidence (endogenous) on local populations may have greater relevancy. }\end{array}$ \\
\hline
\end{tabular}

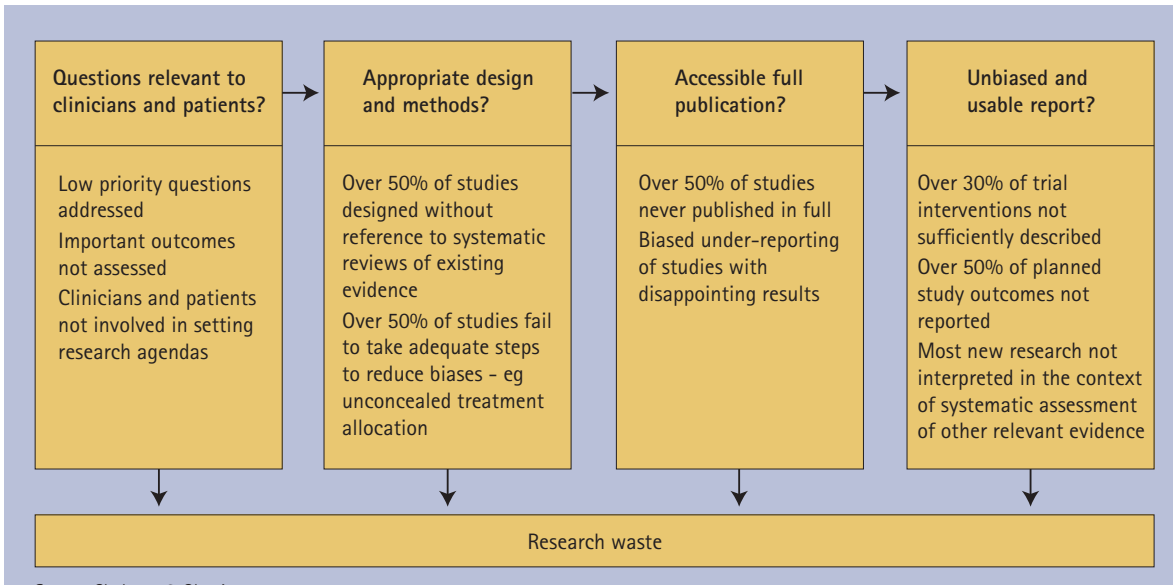

Source: Chalmers \& Glasziou, 2009

Fig. 2 Stages of waste in clinician and patient-relevant research evidence ${ }^{18}$ 


\section{Table 3 Research priority-setting approaches ${ }^{21}$}

\begin{tabular}{l|l}
\hline Priority-setting approach & Features \\
\hline Level & Set research priorities at global/national, regional or institutional level \\
\hline Comprehensiveness & $\begin{array}{l}\text { Focus could be narrow sub-sets of research questions for example, a } \\
\text { specific healthcare field; or wider for example, whole of health sector; or } \\
\text { within a broad context that includes other scientific fields }\end{array}$ \\
\hline $\begin{array}{l}\text { Balance between technical and } \\
\text { interpretive approaches }\end{array}$ & $\begin{array}{l}\text { Technical - emphasises quantifiable epidemiologic or other needs and } \\
\text { costs data; or interpretive - drawing upon the consensus views of } \\
\text { informed participants. }\end{array}$ \\
\hline Stakeholders & $\begin{array}{l}\text { Consultation includes mainly researchers, or wider for example, research } \\
\text { commissioners, research users and communities }\end{array}$ \\
\hline Source: Ranson and Bennett, 200921 &
\end{tabular}

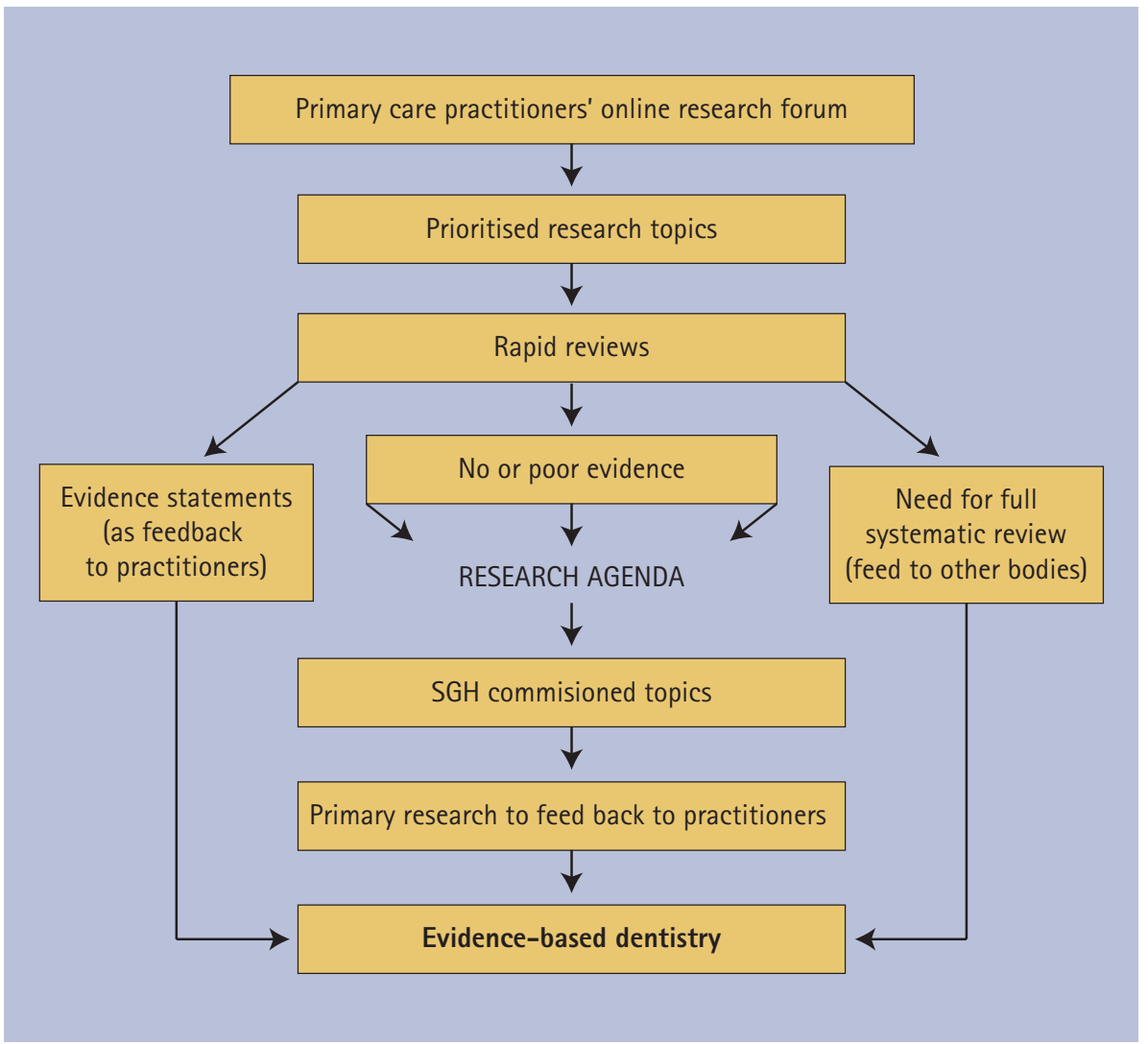

Fig. 3 Process for dental practitioners to influence EBD through research

\section{RESEARCH PRIORITISATION}

There is little consensus as to how best to determine the research agenda for dentistry. Table 3 illustrates approaches adopted by various organisations ${ }^{21}$ and in 2011, the Cochrane Collaboration established an Agenda and Priority Setting Methods Group to try to determine appropriate methodologies for deciding what research should be supported. ${ }^{22}$ Development of appropriate research priority setting methods would seem to be essential if the spending of research funds is to be aligned with real need for evidence. ${ }^{21}$ Uncertainties in practice or policy should drive the prioritisation of research topics, rather than it being the research interests of those carrying out the investigations, which dictate the research agenda.

\section{SUPPORT FOR EVIDENCE-BASED DENTISTRY}

The Shirley-Glasstone Hughes (SGH) Foundation is one of the very few organisations offering funding exclusively to dentally related research projects and it has done so since 1990. Forty-one projects costing a total of £678,000 were funded between 1991 and 2005. An evaluation of the research output from this funding ${ }^{23}$ offered seven recommendations, including an indication that, in order to ensure relevance to 'real-world' dentistry, the SGH Fund should continue to ensure that dentists out-with academic institutions have access to the funding, and that SGH should focus on funding research themes of direct relevance to primary dental care.

In order to adopt these recommendations, the mechanisms by which research commissioning activity could be better informed by the day to day information needs of primary dental care practitioners were explored. An attempt was made to create a process that would encourage as many UK dental practitioners as possible to voice their opinion on what they need to know from research.

A new process (Fig. 3) that allowed dentists to influence the research agenda was launched at the British Dental Association (BDA) annual conference in May 2009. Rapid reviewing of specific topics' available evidence that was integral to the new process was implemented in September 2009. The new process was advertised in this Journal, on the BDA website and at BDA regional meetings.

\section{PRACTITIONER ENGAGEMENT IN RESEARCH AGENDA SETTING}

Unfortunately, very few practitioners took up the opportunity to direct the SGH research agenda using the online approach. Therefore, to try to increase participation, an online topic voting system was introduced. This gave dental practitioners the opportunity to prioritise nominated research topics. The most voted for topic in any voting period (one month duration) became the subject of a rapid evidence review. This involved a researcher undertaking a narrative appraisal of the available evidence relating to the practitioner-prioritised topic. Once a review was complete, an 'evidence statement' or summary was published online and in the BDJ. These jargon-free summaries of the critically-appraised evidence were produced and published ${ }^{24-32}$ in a form whereby the 'pre-digested' evidence could be easily used by a practitioner. Figure 4 describes the full research agenda-setting process as a series of information exchanges.

\section{SO HOW CAN WE ENSURE THAT DENTISTRY BECOMES MORE EVIDENCE-BASED?}

The first step towards promoting evidencebased practice in dentistry is to ensure that evaluation and synthesis of evidence skills are comprehensively embedded in dental training. This will ensure that practitioners with the capability, if not the capacity, to understand and apply research evidence to day to day practice are entering the workforce.

Secondly, in order to overcome the lack of quality evidence which is relevant to the day to day world of a general dental practitioner, it is essential that practitioners put forward to funding bodies the issues and dilemmas they face with their patients, and ask for relevant research to be prioritised and funded. If dentistry is to remain a science, as 


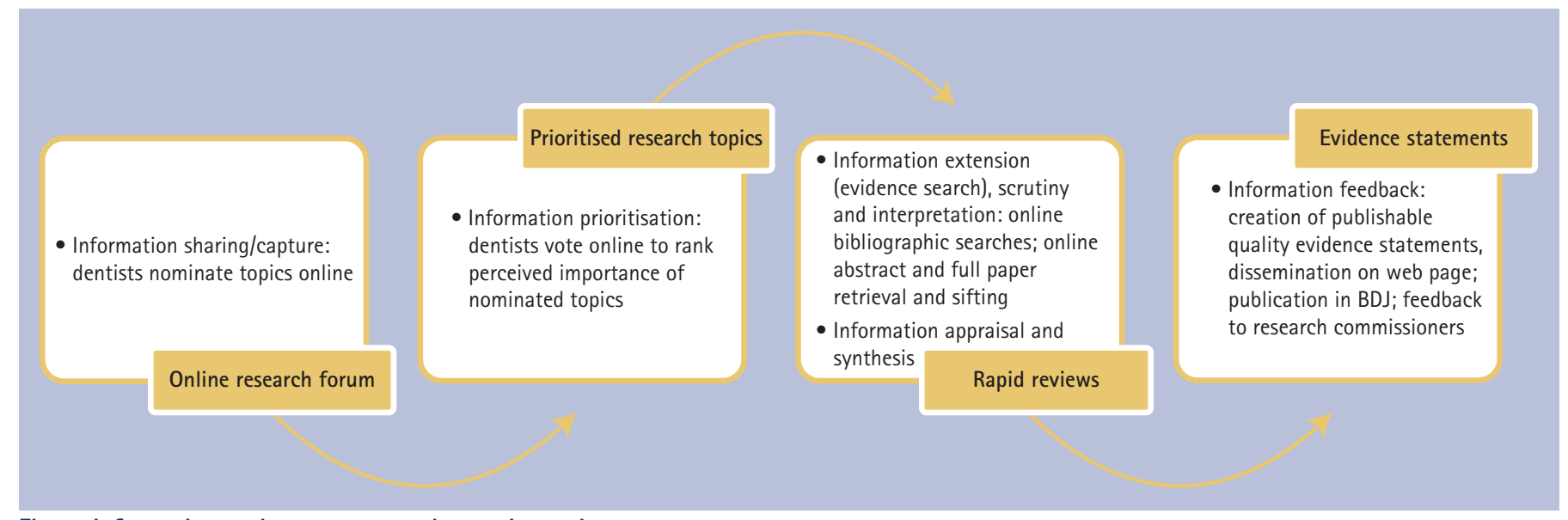

Fig. 4 Information exchange: a research agenda-setting process

well as an art, we need to have appropriate evidence on which to base, and defend, our activities. If practitioners lack a voice in the science underpinning their profession, formulaic guideline/pathway driven dentistry may result.

Furthermore, wider availability of easily accessible pre-processed evidence syntheses on relevant topics, such as the short reviews published in the series by Fox ${ }^{24-33}$ can and should promote interest in, and hopefully the growth of, the application of research evidence in practice. Such short, jargon-free précis of the research evidence have been shown to be appreciated by practitioners ${ }^{34}$ because the average dentist does not have the time to read, digest and synthesise all the evidence on a given topic, and unless evidence review is comprehensive there is always a danger that bias and incorrect conclusions are drawn. While Cochrane reviews meet this 'comprehensiveness' requirement, the bulk of them are impractical for use by practitioners. Thus, the production of research 'synopses' seem to offer a very positive way forward in support of evidence-based dentistry and the BDA/SGH continues to provide these.

Information about the current rapid reviewing provided by the British Dental Association/Shirley Glasstone Hughes Trust is available at Curious About: http://www.bda. org/dentists/education/sgh/about_sgh.aspx

This paper has described a strategy through which practitioners and the BDA can support evidence-based practice, provide useful answers and resources for dentists who wish to involve themselves in research and help set the priorities in dental research.

The next paper in this series will describe the implementation and evaluation of the online system of research prioritisation for dentistry.
1. Cochrane A. Effectiveness and efficiency: random reflections on health services. 3rd ed. Cambridge: Cambridge University Press, 1971.

2. Dawes M, Summerskill W, Glasziou P et al. Sicily statement on evidence-based practice. BMC Med Educ 2005; 5: 1 .

3. Evidence-Based Medicine Working Group. Evidencebased medicine: a new approach to teaching the practice of medicine. JAMA 1992; 268: 2420-2425

4. Abt E. Complexities of an evidence-based clinical practice. Journal of Evidence-Based Dental Practice 2004; 4: 200-209.

5. Kao R. The challenges of transferring evidencebased dentistry into practice. Journal of EvidenceBased Dental Practice 2006; 6: 125-128.

6. Ballini A., Capodiferro S, Toia M et al. Evidencebased dentistry: what's new? Int J Med Sci 2007; 4: 174-178.

7. Department of Health. NHS dental services in England. An independent review led by Professor Jimmy Steele. London: DH, 2009.

8. Chiappelli F, Prolo P, Neagos N et al. Tools and methods for evidence-based research in dental practice: preparing the future. Journal of Evidence-Based Dental Practice 2004; 4: 16-23.

9. Meyer D. The ADA perspective. Real-world implementation of evidence-based dental practice. Journal of Evidence-Based Dental Practice 2006; 6: 111-115.

10. Sequeira P. Critically appraised topics (CATs): bringing evidence to the chairside (1). Evidence-Based Dentistry 2000; 2: 107-109.

11. American Dental Association. Question of the month. J Am Dent Assoc 2003; 134: 690.

12. Cruz M. Real-world implementation of evidencebased dental practice: introduction. Journal of Evidence-Based Dental Practice 2006; 6: 110.

13. McGlone P, Watt R, Sheiham A. Evidence-based dentistry: an overview of the challenges in changing professional practice. Br DentJ 2001; 190: 636- 639.

14. Matthews, J. The evidence on emerging issues: providing patient care in the absence of evidence. Journal of Evidence-Based Dental Practice 2009; 9: 135-138.

15. Scholey J, Harrison J. Publication bias: raising awareness of a potential problem in dental research. Br Dent J 2003; 194: 235-237.

16. Wardh I, Axelsson S, Tegelberg, A. Which evidence has an impact on dentists' willingness to change their behavior? Journal of Evidence-Based Dental Practice 2009; 9: 197-205.

17. Hay M, Weisner T, Subramanian S, Duan N, Niedzinski E, Kravitz R. Harnessing experience: exploring the gap between evidence-based medicine and clinica practice. J Eval Clin Pract 2008; 14: 707-713.

18. Chalmers I, Glasziou P. Avoidable waste in the production and reporting of research evidence. Lancet 2009; 374: 86-89.

19. Pub Med 'dental' article listing. Online search available at http://www.ncbi.nlm.nih.gov/ pubmed/?term=dental (accessed June 2014)

20. Maskrey N, Underhill J, Hutchinson A, Shaughnessy A, Slawson D. Getting a better grip on research: the maze of the most busy life. InnovAlT 2010; 3 : 172-179.

21. Ranson M K, Bennett S C. Priority setting and health policy and systems research. Health Res Policy Syst 2009; 7: 27.

22. Cochrane Agenda and Priority Setting Methods Group. Scope of our work. The Cochrane Collaboration, 2012. Online information available at http://capsmg.cochrane.org/scope-our-work (accessed June 2014)

23. Miguel J C, Kay E J, Lowe J C. Shirley Glasstone Hughes memorial prize for dental research: an evaluation of the output 15 years after the Trust's inception. Br Dent J 2007; 203: 535-541.

24. Caines B. Evidence summary: why is access to dental care for frail elderly people worse than for other groups? Br Dent J 2010; 208: 119-122.

25. Fox C. Evidence summary: what is the effectiveness of alternative approaches for increasing dental attendance by poor families or families from deprived areas? Br Dent J 2010; 208: 167-171.

26. Fox C. Evidence summary: how can dietary advice to prevent dental erosion be effectively delivered in UK general dental practice? Br Dent J 2010; 208: 217-218.

27. Fox C. Evidence summary: what do dentists mean by 'prevention' when applied to what they do in their practices? Br Dent J 2010; 208: 359-363.

28. Fox C. Evidence summary: do people living in deprived areas define oral health differently from people who live in less deprived areas? Br Dent J 2010; 208: 411-412.

29. Fox C. Evidence summary: does 'routine' scaling have any beneficial effects, or is it a waste of time? Br Dent J 2010; 208: 477-478.

30. Fox C. Evidence summary: What 'cost-of-illness' evidence is there about cross-infection-related infections in dental practice? Br Dent J 2010; 209: 87-88.

31. Fox C. Evidence summary: Does dentists' fear have an adverse effect on clinical decision-making? $\mathrm{Br}$ Dent J 2010; 209: 181-182.

32. Fox C. Evidence summary: what do we know from qualitative research about peoples' care-seeking about oral health? Br Dent J 2010; 209: 225-231.

33. Fox C. Evaluation of a process for research agendasetting in primary dental care. PhD thesis, Peninsula College of Medicine and Dentistry, 2012.

34. British Dental Association Research Unit. Omnibus survey - England. October- November 2010. London BDA, 2010. 